\title{
GFAAS Determination of Antimony, Barium, and Lead Levels in Gunshot Residue Swabs: An Application in Forensic Chemistry
}

\author{
*Bayram Yüksel ${ }^{\mathrm{a}}$, Aynur Ozler-Yigiter ${ }^{\mathrm{a}}$, Taner Bora ${ }^{\mathrm{a}}$, Nilgün Sen ${ }^{\mathrm{b}}$, and Zeliha Kayaalti ${ }^{\mathrm{c}}$ \\ a Turkish National Police, Ankara Police Forensic Laboratory, Gölbasi, 06830 Ankara, Turkey \\ b Turkish National Police Academy, Institute of Forensic Sciences, Anittepe, 06570 Ankara, Turkey \\ ${ }^{c}$ Ankara University, Institute of Forensic Sciences, Dikimevi, 06590 Ankara, Turkey
}

\section{INTRODUCTION}

The determination of gunshot residue (GSR) evidence in the field of forensic science is an important aspect of forensic analysis in firearm-related cases. The term "GSR" can be defined as a combination of unburnt and partially burnt propellant powder as well as particles from the ammunition primer, smoke, grease, lubricants, and metals from the cartridge $(1,2)$. The inorganic oxides present in the primer, such as lead styphanate, antimony sulfide, and barium nitrate, are the most important compounds in terms of GSR analysis (3). When the firing pin collides with the primer and burns it, GSR breaks out from the gun through any available opening in the weapon in the form of a vapor or "plume" around the person. Combustion of these compounds results in fast thermal degradation and vaporization. Then it solidifies into extremely small $(<10 \mu \mathrm{m})$ fine oxide particles and settles on the hands, clothing, and all surfaces in the immediate proximity of the discharged weapon $(3,4)$. A typical firearm cartridge consists of primer, powder charge, bullet, and case (Figure 1).

The inorganic GSR, such as nitrates, nitrites, and metallic particles, arise from the primer and propellant as well as the cartridge case, the projectile jacket or its core, and from the weapon barrel itself $(1,5$, 6). In addition to these inorganic

Corresponding author.

E-mail: bayramyuksel83@gmail.com

Tel./Fax: +90 312 4629565/

+903124629429

\section{ABSTRACT}

A sensitive and simple method has been developed and validated to determine the barium, lead, and antimony levels in gunshot residue (GSR) hand swabs for routine forensic chemistry applications using graphite furnace atomic absorption spectrometry (GFAAS), equipped with Zeeman background correction. The main purpose and the novelty of this paper fundamentally depend on assessment of the lifetime of GSR metals on the hands in terms of length of time after firing. The firearm used for the forensic GSR hand swab study was a Sarsilmaz Kilinc Mega 2000 pistol loaded with MKE $9 \mathrm{~mm} \times 19$ parabellum ammunition. The hand swab samples were collected from officers of the Turkish national police and were sampled at five different times after firing $(0,1,2,3$ and 4 hours, respectively). Prior to analysis, the samples were pretreated by addition of $5 \mathrm{~mL}$ of $8 \%$ (v/v) nitric acid, then shaken at $200 \mathrm{rpm}$ (rotation per minute) for 30 minutes. Precision and accuracy of the GSR analysis method was validated by using certified reference materials. The recovery and relative standard deviation (RSD\%) values obtained for antimony, barium, and lead were $103.21 \%$ and $1.27 \%$, $101.36 \%$ and $3.24 \%$, and $99.22 \%$ and $2.30 \%$, respectively. The method showed linearity in the range of $0-200 \mu \mathrm{g} / \mathrm{L}$ for antimony and barium, and $0-100 \mu \mathrm{g} / \mathrm{L}$ for lead. The detection and quantification limits for antimony, barium, and lead were found to be $3.30 \mu \mathrm{g} / \mathrm{L}$ and $9.90 \mu \mathrm{g} / \mathrm{L}, 11.94$ $\mu \mathrm{g} / \mathrm{L}$ and $35.85 \mu \mathrm{g} / \mathrm{L}, 56.22 \mu \mathrm{g} / \mathrm{L}$ and $168.82 \mu \mathrm{g} / \mathrm{L}$, respectively. components, many organic compounds are present in the primer and gunpowder (4), such as ethyl centralite (EC), diphenylamine (DPA), and its nitration products, n-nitrosodiphenylamine (N-NODPA) and 2-nitrodiphenylamine (2-NDPA) $(7,8)$. Many different techniques for gunshot residue (GSR) analysis are reported in the literature (4). Early methods, such as the nitrate tests, have been replaced by modern techniques. The current methods include inductively coupled plasma mass spectroscopy (ICPMS), flame atomic absorption spectrometry (FAAS), electrothermal atomic absorption spectrometry (ETAAS), graphite furnace atomic absorption spectrometry (GFAAS), neutron activation analysis (NAA), component analysis employing $\mathrm{X}$-ray fluorescence (XRF), protoninduced X-ray emission (PIXE), and scanning electron microscopy/ energy dispersive X-ray (SEM/EDX) spectroscopy (1, 9-18). Furthermore, ion mobility spectrometry and liquid chromatography coupled with mass spectrometry (LC-MS)

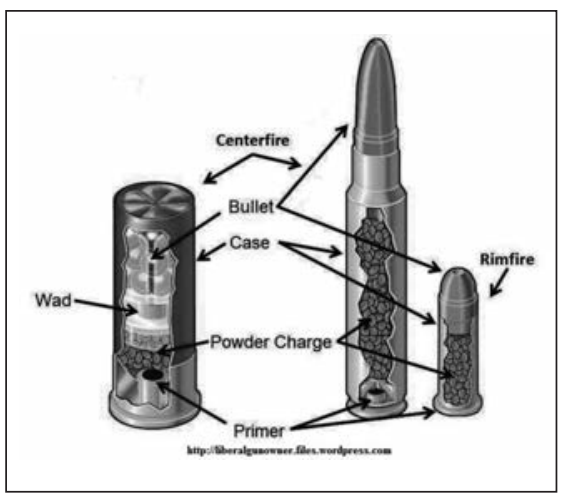

Fig 1. Schematic diagram of typical cartridges. (Access Date: 11/03/05). bttp://liberalgunowner.files.wordpress. com 
(3) can be used for the detection and identification of organic gunshot residue (OGSR). Scanning electron microscopy (SEM) for the analysis of inorganic gunshot residues (IGSR) was introduced in 1974 by the Aerospace Corporation, USA (19). SEM was coupled with energy dispersive spectroscopy (SEM/EDS) which facilitated to obtain both morphological information and the elemental composition of the particles (4). Next, X-ray was added and SEM-EDX became a very beneficial and non-destructive methodology (20). However, SEMEDX is one of the most expensive instruments for use in the analysis of the elemental composition of GSR. GFAAS, on the other hand, is much more economical, offers high selectivity and sensitivity in the detection of a wide range of metals and non-metals, including antimony $(\mathrm{Sb})$, barium $(\mathrm{Ba})$, and lead $(\mathrm{Pb})$.

The objective of this study was to develop and validate a sensitive method using GFAAS, equipped with Zeeman background correction, to determine antimony, barium and lead concentrations in gunshot residue swab samples as a routine forensic chemistry application. The hand swab samples of the shooters were obtained at 5 different time intervals after firing $(0,1$, 2,3 and 4 hours, respectively). Hence, it was also aimed to investigate the lifetime of gunshot residue $(\mathrm{Sb}, \mathrm{Ba}$, and $\mathrm{Pb})$ on the hands in terms of length of time after firing.

\section{EXPERIMENTAL}

\section{Instrumentation}

All $\mathrm{Sb}, \mathrm{Ba}$, and $\mathrm{Pb}$ measurements were performed using an Agilent AA280Z graphite furnace atomic absorption spectrometer (Agilent, USA), equipped with Zeeman background correction. Boosted discharge hollow cathode lamps were used as the excitation source. The GFAAS instrumental operating parameters are listed in Table I.

\section{Standard Solutions and Reagents}

The stock solutions (1000 $\mu \mathrm{g} / \mathrm{mL}$ ) of antimony, barium, and lead were obtained from SCP Science AA Standards (Canada). Nitric acid $\left(\mathrm{HNO}_{3}, 65 \% \mathrm{v}: \mathrm{v}\right)$ was purchased from Merck (Darmstadt, Germany). All chemicals used for this work were of analytical reagent grade unless otherwise specified. Ultrapure water (Merck-Millipore ${ }^{\circledR}$ Direct-Q8 ${ }^{\circledR}$, Germany) with a resistivity of $18 \mathrm{M} \Omega \cdot \mathrm{cm}$ was used to prepare the solutions. Argon gas with a purity of $99.999 \%$ was purchased from a local supplier (Vasak Gaz, Ankara, Turkey). Certified reference solutions $(100 \mu \mathrm{g} / \mathrm{L})$ of antimony, barium, and lead were obtained from High Purity Standards (Charleston, NC, USA).

\section{Sample Collection}

The firearm used for this study was a Sarsilmaz Kilinc Mega 2000 (Düzce, Turkey) loaded with MKE $9 \mathrm{~mm} \times 19$ parabellum ammunition

\section{Atomic Spectroscopy $\bigcirc$ Vol. 37(4), July/August 2016}

(Ankara, Turkey). The GSR hand swab samples were collected from officers of the Turkish national police who were recruited to do the specified shooting at the shooting range of the Ballistic Investigation Section of Ankara Police Forensic Laboratory in Gölbasi, Ankara, Turkey. Adhesive hand swabs were collected from 50 different shooters at five different time intervals after firing $(0,1,2,3$ and 4 hours, respectively). For each time, 10 different hand swabs were taken from the individuals. This work was ethically approved by the Directory of Ankara Police Forensic Laboratory, Turkish National Police, Ankara, Turkey (Decision Number: 21815799.4517.(91265)/00330/08. 01.2016). Each volunteer was given a written informed consent form in accordance with the principles as established in The Declaration of Helsinki (World Medical Association, Declaration of Helsinki, 1964).

The swab samples were medicaltype adhesive plaster bands pur-

TABLE I

Operating Parameters for GFAAS System

\begin{tabular}{llll}
\hline Element - Matrix & Sb-GSR & Ba-GSR & Pb-GSR \\
Instrument & Zeeman & Zeeman & Zeeman \\
Concentration Unit & $\mu \mathrm{g} / \mathrm{L}$ & $\mu \mathrm{g} / \mathrm{L}$ & $\mu \mathrm{g} / \mathrm{L}$ \\
Instrument Mode & Absorbance & Absorbance & Absorbance \\
Sampling & Auto-Mix & Auto-Mix & Auto-Mix \\
Calibration Mode & Concentration & Concentration & Concentration \\
Measurement Mode & Peak Height & Peak Height & Peak Height \\
Replicates Standard & 3 & 3 & 3 \\
Replicate Sample & 3 & 3 & 3 \\
Expansion Factor & 1.0 & 1.0 & 1.0 \\
Wavelength & $217.6 \mathrm{~nm}$ & $553.6 \mathrm{~nm}$ & $: 283.3 \mathrm{~nm}$ \\
Slit Width & $0.2 \mathrm{~nm}$ & $0.5 \mathrm{R} \mathrm{nm}$ & $0.5 \mathrm{~nm}$ \\
Gain & $66 \%$ & $41 \%$ & $44 \%$ \\
Current & $10.0 \mathrm{~mA}$ & $20.0 \mathrm{~mA}$ & $10.0 \mathrm{~mA}$ \\
Background & $\mathrm{BC} \mathrm{on}$ & $\mathrm{BC}$ on & BC on \\
Standard 1 & $20.0 \mu \mathrm{g} / \mathrm{L}$ & $40.0 \mu \mathrm{g} / \mathrm{L}$ & $20.0 \mu \mathrm{g} / \mathrm{L}$ \\
Standard 2 & $40.0 \mu \mathrm{g} / \mathrm{L}$ & $60.0 \mu \mathrm{g} / \mathrm{L}$ & $40.0 \mu \mathrm{g} / \mathrm{L}$ \\
Standard 3 & $60.0 \mu \mathrm{g} / \mathrm{L}$ & $80.0 \mu \mathrm{g} / \mathrm{L}$ & $60.0 \mu \mathrm{g} / \mathrm{L}$ \\
Standard 4 & $80.0 \mu \mathrm{g} / \mathrm{L}$ & $100 \mu \mathrm{g} / \mathrm{L}$ & $80.0 \mu \mathrm{g} / \mathrm{L}$ \\
Reslope Standard & Standard 2 & Standard 2 & Standard 2 \\
Recalibration Rate & 50 & 50 & 50 \\
Calibration Algorithm & Linear & Linear & Linear \\
\hline
\end{tabular}


chased from a local supplier (Beta Ipek, Turkey). The sections of the hand used for sampling the gunshot residue were web and palm, as is shown in Figure 2.

\section{Procedure}

In order to prepare calibration standards at the concentrations of 20.0, 40.0, 60.0, 80.0, and 100 $\mu \mathrm{g} / \mathrm{L}$, a $1000 \mu \mathrm{g} / \mathrm{mL}$ in $4 \% \mathrm{HNO}_{3}$ antimony, barium, and lead stock solution was diluted in $4 \%(\mathrm{v}: \mathrm{v})$ $\mathrm{HNO}_{3}$. All glassware was kept in $10 \%$ (v:v) nitric acid for at least one night prior to the start of each experiment. Prior to analysis, the samples were pre-treated with addition of $5 \mathrm{~mL}$ of $8 \%(\mathrm{v} / \mathrm{v})$ nitric acid and shaken at $200 \mathrm{rpm}$ (rotation per minute) for 30 minutes.

\section{Optimization and Sample Treatment}

In order to achieve best performance from this spectroscopic GSR analysis, some important parameters were adjusted. The major criteria included selection of the appropriate wavelength for the matrix, selection of concentration range in accordance with the elemental concentration in real GSR hand swab samples, evaluating the best furnace program, and establishing the linearity. The graphite furnace temperature programs for antimony, barium, and lead are listed in Tables II, III, and IV, respectively. Detection of the metals was performed at the wavelength of $217.6 \mathrm{~nm}$ for $\mathrm{Sb}, 553.6 \mathrm{~nm}$ for $\mathrm{Ba}$, and $283.3 \mathrm{~nm}$ for $\mathrm{Pb}$. The proposed method showed linearity in the range of $0-200 \mu \mathrm{g} / \mathrm{L}$ for antimony and barium, while for lead it was $0-100 \mu \mathrm{g} / \mathrm{L}$. Calibration standards at the concentrations of 20.0, $40.0,60.0,80.0$, and $100.0 \mu \mathrm{g} / \mathrm{L}$ were prepared for antimony (except for 100.0), barium (except for 20.0), and lead (except for 100.0). The calibration graphs for antimony, barium, and lead showed good linearity in the concentration

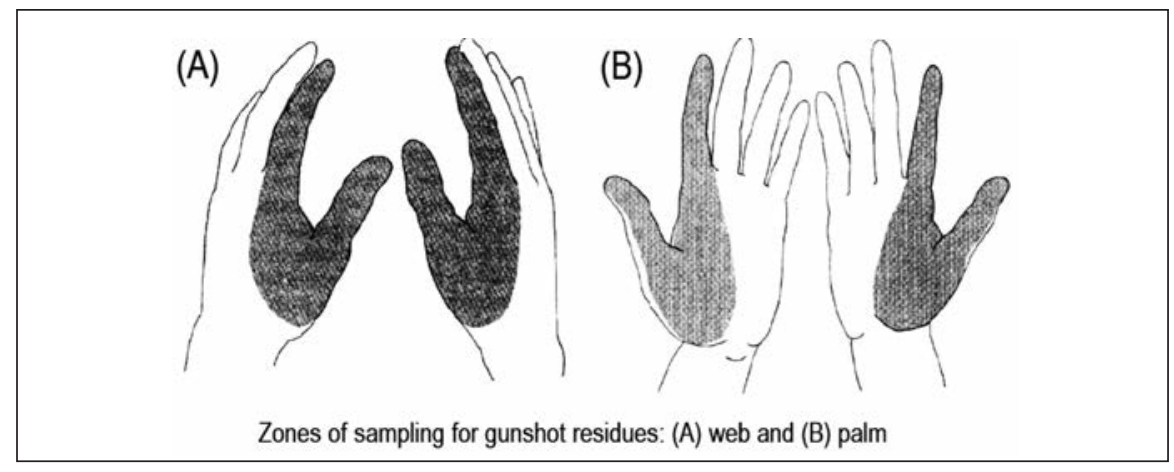

Fig 2. Zones on hands of sampling for gunshot residues: (A) web and (B) palm.

TABLE II

Graphite Furnace Temperature Program for Antimony

\begin{tabular}{cccccccc}
\hline Step & $\begin{array}{c}\text { Temp. } \\
\left({ }^{\circ} \mathrm{C}\right)\end{array}$ & $\begin{array}{c}\text { Time } \\
(\mathrm{s})\end{array}$ & $\begin{array}{c}\text { Flow } \\
(\mathrm{L} / \mathrm{min})\end{array}$ & \multicolumn{2}{c}{$\begin{array}{c}\text { Signal } \\
\text { Collection }\end{array}$} & Reading \\
\hline 1 & 65 & 5.0 & 0.3 & $\times$ & No & $\times$ & No \\
2 & 95 & 2.0 & 0.3 & $\times$ & No & $\times$ & No \\
3 & 120 & 8.0 & 0.3 & $\times$ & No & $\times$ & No \\
4 & 350 & 10.0 & 0.3 & $\times$ & No & $\times$ & No \\
5 & 700 & 13.0 & 0.3 & $\times$ & No & $\times$ & No \\
6 & 2700 & 1.0 & 0.0 & $\sqrt{ }$ & Yes & $\sqrt{ }$ & Yes \\
7 & 2700 & 0.6 & 0.0 & $\sqrt{ }$ & Yes & $\sqrt{ }$ & Yes \\
8 & 2700 & 3.0 & 0.3 & $\times$ & No & $\times$ & No \\
\hline
\end{tabular}

TABLE III

Graphite Furnace Temperature Program for Barium

\begin{tabular}{cccccccc}
\hline Step & $\begin{array}{c}\text { Temp. } \\
\left({ }^{\circ} \mathrm{C}\right)\end{array}$ & $\begin{array}{c}\text { Time } \\
(\mathrm{s})\end{array}$ & $\begin{array}{c}\text { Flow } \\
(\mathrm{L} / \mathrm{min})\end{array}$ & \multicolumn{2}{c}{$\begin{array}{c}\text { Signal } \\
\text { Collection }\end{array}$} & Reading \\
\hline 1 & 85 & 5.0 & 0.3 & $\times$ & No & $\times$ & No \\
2 & 95 & 40.0 & 0.3 & $\times$ & No & $\times$ & No \\
3 & 120 & 10.0 & 0.3 & $\times$ & No & $\times$ & No \\
4 & 400 & 6.0 & 0.3 & $\times$ & No & $\times$ & No \\
5 & 400 & 2.0 & 0.0 & $\sqrt{ }$ & Yes & $\times$ & No \\
6 & 2600 & 1.1 & 0.0 & $\sqrt{ }$ & Yes & $\sqrt{ }$ & Yes \\
7 & 2600 & 2.0 & 0.0 & $\sqrt{ }$ & Yes & $\sqrt{ }$ & Yes \\
8 & 2700 & 2.0 & 0.3 & $\times$ & No & $\times$ & No \\
\hline
\end{tabular}

TABLE IV

Graphite Furnace Temperature Program for Lead

\begin{tabular}{cccccccc}
\hline Step & $\begin{array}{c}\text { Temp. } \\
\left({ }^{\circ} \mathrm{C}\right)\end{array}$ & $\begin{array}{c}\text { Time } \\
(\mathrm{s})\end{array}$ & $\begin{array}{c}\text { Flow } \\
(\mathrm{L} / \mathrm{min})\end{array}$ & $\begin{array}{c}\text { Signal } \\
\text { Collection }\end{array}$ & Reading \\
\hline 1 & 85 & 5.0 & 0.3 & $\times$ & No & $\times$ & No \\
2 & 95 & 40.0 & 0.3 & $\times$ & No & $\times$ & No \\
3 & 120 & 10.0 & 0.3 & $\times$ & No & $\times$ & No \\
4 & 400 & 6.0 & 0.3 & $\times$ & No & $\times$ & No \\
5 & 400 & 2.0 & 0.0 & $\sqrt{ }$ & Yes & $\times$ & No \\
6 & 2100 & 0.9 & 0.0 & $\sqrt{ }$ & Yes & $\sqrt{ }$ & Yes \\
7 & 2100 & 2.0 & 0.0 & $\sqrt{ }$ & Yes & $\sqrt{ }$ & Yes \\
8 & 2100 & 2.0 & 0.3 & $\times$ & No & $\times$ & No \\
\hline
\end{tabular}


range examined (Figure 3, Figure 4, and Figure 5, respectively). The correlation coefficient (r) and equation of the calibration curves for antimony were respectively found to be $\mathrm{r}=0.9997$ and the Abs $=0.0045 \mathrm{C}+0.0077$, where Abs stands for integrated absorbance and $\mathrm{C}$ the antimony concentration in $\mu \mathrm{g} / \mathrm{L}$. Similarly, the values for barium were $\mathrm{r}=0.9997$ and $\mathrm{Abs}=0.0013 \mathrm{C}+0.0012$, and for lead $\mathrm{r}=0.9998$ and

$\mathrm{Abs}=0.0032 \mathrm{C}+0.0028$.

\section{Method Validation}

To validate the method in terms of accuracy, precision, and recovery, certified reference solutions of $100 \mu \mathrm{g} / \mathrm{L}$ antimony, barium, and lead (High Purity Standards,

Charleston, USA) were analyzed 10 times with triplicate measurements. The results were compared with the certified values for accuracy,

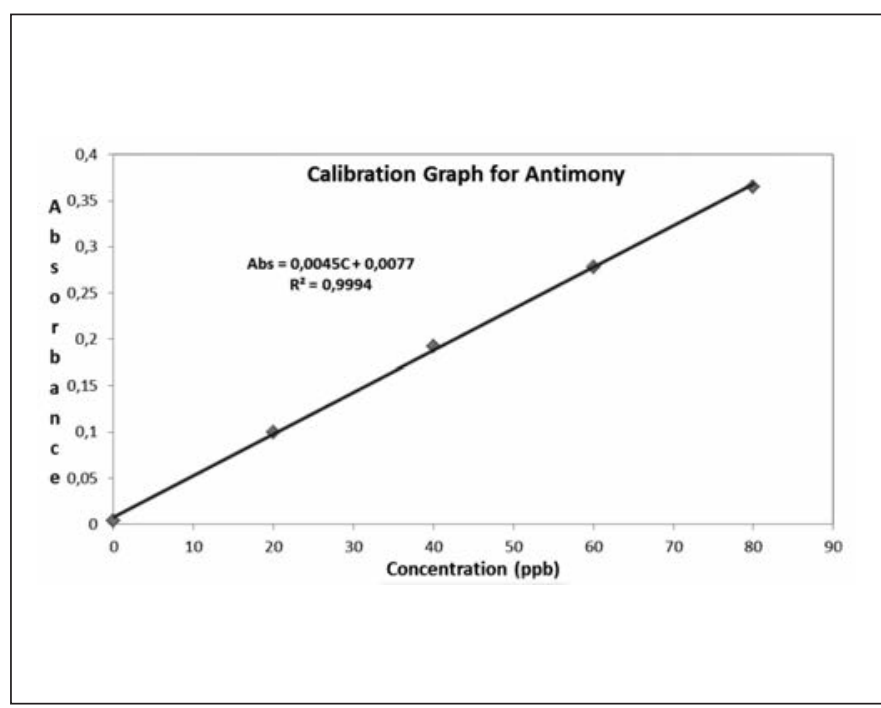

Fig 3. Calibration graph of antimony, performed by GFAAS, equipped with Zeeman-effect background correction.

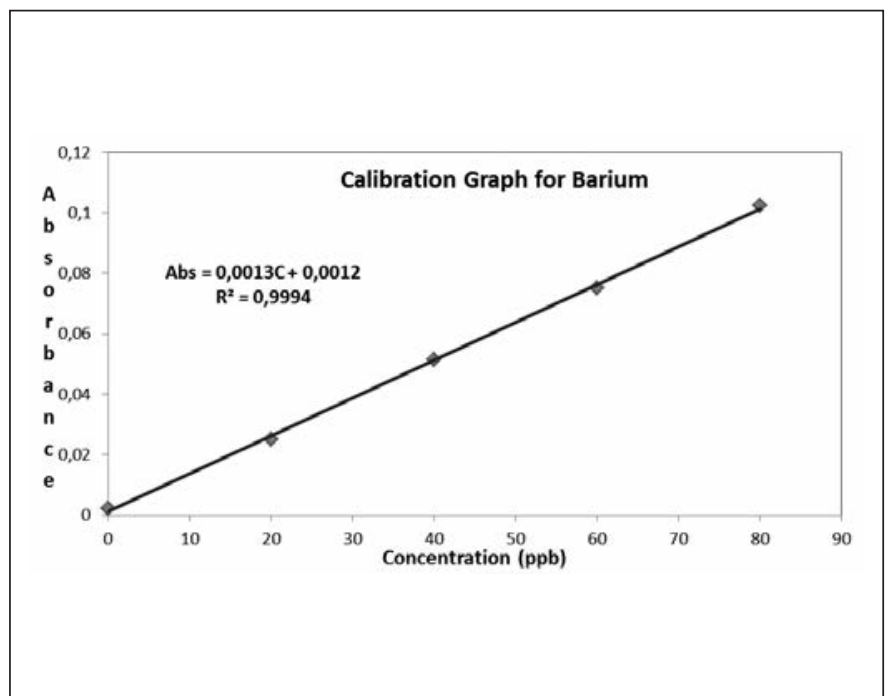

Fig 4. Calibration graph of barium, performed by GFAAS, equipped with Zeeman-effect background correction.

\section{Atomic Spectroscopy \\ $\bigcirc$ Vol. 37(4), July/August 2016}

precision, and recovery of the method (see Table V). The precision of the methods were expressed as the relative standard deviation (RSD) of 10 independent analyses of the certified reference materials. The certified value for antimony, barium and lead was $100 \pm 0.5 \mu \mathrm{g} / \mathrm{L}$, while the measured values for antimony, barium, and lead were $103.21 \pm 1.32 \mu \mathrm{g} / \mathrm{L}$, $101.36 \pm 3.29 \mu \mathrm{g} / \mathrm{L}, 99.22 \pm 2.29$ $\mu \mathrm{g} / \mathrm{L}$, respectively. The recovery and relative standard deviation (RSD) for antimony, barium, and lead were $103.21 \%$ and $1.27 \%$, $101.36 \%$ and $3.24 \%, 99.22 \%$ and $2.30 \%$, respectively. According to these results, good agreement was obtained between the certified values and the measured $\mathrm{Sb}, \mathrm{Ba}$, and $\mathrm{Pb}$ concentrations.

TABLE V

Analysis of Certified Reference Materials

\begin{tabular}{cccccc}
\hline CRMs & $\begin{array}{c}\text { No. of } \\
\text { Analyses } \\
(\mathrm{n})\end{array}$ & $\begin{array}{c}\text { Certified } \\
\text { Value } \\
(\mu \mathrm{g} / \mathrm{L})\end{array}$ & $\begin{array}{c}\text { Measured } \\
\text { Value } \\
(\mu \mathrm{g} / \mathrm{L})\end{array}$ & $\begin{array}{c}\text { Recovery } \\
(\%)\end{array}$ & $\begin{array}{c}\text { RSD } \\
(\%)\end{array}$ \\
\hline $\mathrm{Sb}$ & 10 & 100.0 & $103.21 \pm 1.32$ & 103.21 & 1.27 \\
$\mathrm{Ba}$ & 10 & 100.0 & $101.36 \pm 3.29$ & 101.36 & 3.24 \\
$\mathrm{~Pb}$ & 10 & 100.0 & $99.22 \pm 2.29$ & 99.22 & 2.30
\end{tabular}

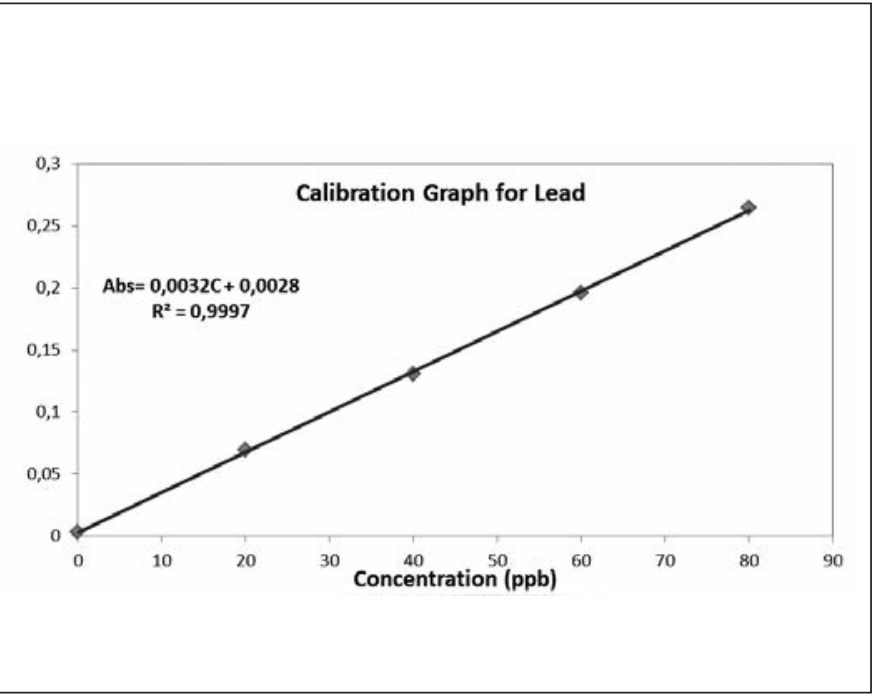

Fig 5. Calibration graph of lead, performed by GFAAS, equipped with Zeeman-effect background correction. 


\section{Limit of Detection and Quantification}

The limit of detection (LOD) and lowest limit of quantification (LOQ) were determined based on the standard deviation of the response and the slope of the calibration curve, based on ICH guidelines $(21,22)$ $(\mathrm{LOD}=3.3 \sigma / \mathrm{S}, \mathrm{LOQ}=10 \sigma / \mathrm{S}$, where $\sigma$ is the standard deviation of the response and $\mathrm{S}$ is the slope of the calibration curve). The GFAAS method for GSR analysis provided LOD and LOQ for antimony, barium and lead equal to $3.30 \mu \mathrm{g} / \mathrm{L}$ and $9.90 \mu \mathrm{g} / \mathrm{L}, 11.94 \mu \mathrm{g} / \mathrm{L}$ and 35.85 $\mu \mathrm{g} / \mathrm{L}, 56.22 \mu \mathrm{g} / \mathrm{L}$ and $168.82 \mu \mathrm{g} / \mathrm{L}$, respectively. To assess the significance of GSR elements detected, the LOQ values obtained are important since the LOQ can be defined as the lowest concentration at which the analyte cannot only be accurately detected but at which some predetermined goals for bias, imprecision, and total error are met.

\section{RESULTS AND DISCUSSION}

Elemental analysis of GSR is one of the most important and critical pieces of evidence in the investigation of a criminal event related to

TABLE VI Significant GSR Levels (26)

\begin{tabular}{lrrr}
\hline Unit & Sb & $\mathrm{Ba}$ & $\mathrm{Pb}$ \\
\hline ng/swab & 35 & 150 & 800 \\
$\mu \mathrm{g} / \mathrm{L}$ & 7 & 30 & 160 \\
\hline
\end{tabular}

firearm discharge cases. The primer mixture in GSR contains lead styphnate (initiatory), barium nitrate (oxidizer), and antimony sulfide (fuel) which is burned as a result of the firing pin hitting the primer cap of the ammunition when the trigger of the firearm is pulled. It is defined as being unique to GSR where $\mathrm{Sb}$, $\mathrm{Ba}$, and $\mathrm{Pb}$ combine into a single particle since there is no other known source of this compound. Each individual element or other combinations of these elements are classified as characteristic of GSR (4). In other words, some answers to the question of "accepted uniqueness" (23) of GSR particles can be provided by the determination of $\mathrm{Sb}, \mathrm{Ba}, \mathrm{Pb}$.

The lifetime of GSR remaining on the hands is an essential consideration in events where the suspect is not arrested promptly after the incident $(24,25)$. In the literature, the length of time at which GSR was detected ranges from 1 hour to 48 hours. Loss of GSR can be due to many reasons such as washing or rinsing the hands, rubbing them against materials, putting them in the pockets, or being handcuffed in the back (26). Levels of the metals are considered significant only when they are above $35 \mathrm{ng} / \mathrm{swab}$ for antimony, 150 $\mathrm{ng} / \mathrm{swab}$ for barium, and 800 ng/swab for lead (27) (Table VI). The LOQ values obtained with the proposed method were also verified.

TABLE VII

Detected GSR Concentration After Firing

\begin{tabular}{cccc}
\hline $\begin{array}{c}\text { Time } \\
(\mathrm{h})\end{array}$ & $\begin{array}{c}\mathrm{Pb} \\
(\mu \mathrm{g} / \mathrm{L})\end{array}$ & $\begin{array}{c}\mathrm{Ba} \\
(\mu \mathrm{g} / \mathrm{L})\end{array}$ & $\begin{array}{c}\mathrm{SB} \\
(\mu \mathrm{g} / \mathrm{L})\end{array}$ \\
\hline 0 & $5200 \pm 422$ & $1120 \pm 80.3$ & $102.41 \pm 8.94$ \\
1 & $3370 \pm 222$ & $116.5 \pm 10.7$ & $19.47 \pm 2.32$ \\
2 & $2604 \pm 179$ & $83.3 \pm 5.59$ & $15.93 \pm 1.76$ \\
3 & $2403 \pm 160$ & $59.5 \pm 4.94$ & $15.21 \pm 2.10$ \\
4 & $1346 \pm 89.7$ & $27.16 \pm 2.81$ & $5.21 \pm 3.34$ \\
\hline
\end{tabular}




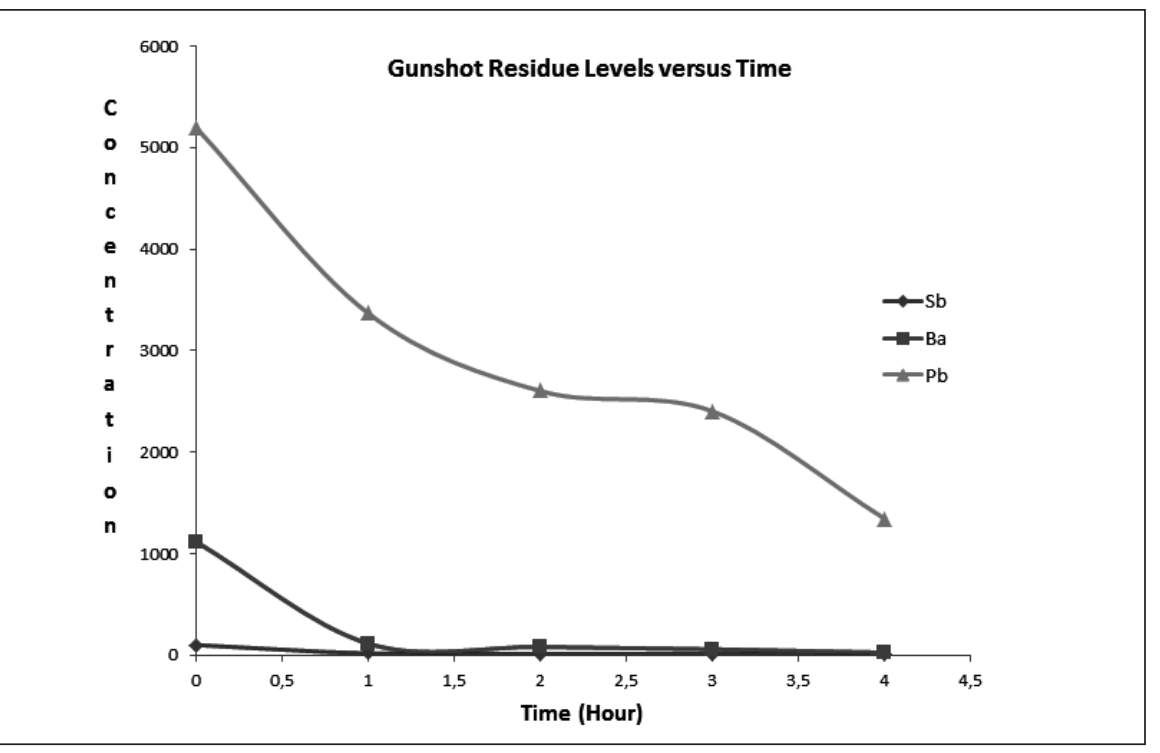

Fig 6. GSR levels versus time. The upper line represents the Pb levels $(\mu g / L) v s$. time (b), while the middle and bottom lines represent Ba and Sb, respectively.

ues. The main purpose and the novelty of this paper fundamentally depend on assessment of the lifetime of GSR metals on the hands in terms of length of time after firing. Therefore, it can be suggested that the first 3 hours after firing are critical for the crime scene investigators (CSI). In order not to have false-negatives, CSI should collect the samples within the first 3 hours since the levels of GSR metals on the hands of the suspects decrease dramatically at the time intervals studied.

\section{ACKNOWLEDGMENT}

The authors would like to thank to Turkish National Police, Ankara Police Forensic Laboratory, for the financial support and permission of the study (Decision Number: 21815799.4517.(91265)/00330/08. 01.2016).

Received November 4, 2015.

\section{REFERENCES}

1. E. Turillazzi, G.P. Di Peri, A. Nieddu, S. Bello, F. Monaci, M. Neri, C. Pomara, R. Rabozzi, I. Riezzo, and V. Fineschi, Forensic Sci. Int. 231(1-3), 142 (2013).

2. O. Dalby, D. Butler and J.W. Birkett, J. Forensic Sci. 55, 924 (2010).

3. J. Moran and S. Ehart Bell, Int. J. Ion Mobil. Spec. 16, 247 (2013).

4. A.J. Schwoeble and D.L. Exline, Current Methods in Forensic Gunshot Residue Analysis, CRC Press LLC (2000).

5. Z. Brozek-Mucha, Forensic Sci. Int. 210, 31 (2011).

6. Z. Brozek-Mucha, X-ray Spectrom. 36,398 (2007).

7. M. Zhao, S. Zhang, C. Yang, Y. Xu, Y. Wen, L. Sun and $X$. Zhang, J Forensic Sci 53, 807 (2008)

8. J. Arndt, S. Bell, L. Crookshanks, M. Lovejoy, C. Oleska, T. Tulley and D. Wolfe, Forensic Sci Int 222, 137 (2012)

9. S.S. Krishnan, J. Forensic Sci. 19, 351 (1974)

10. A. Seamster, T. Mead, J. Gislason, K. Jackson, F. Ruddy and B.D. Pate, J. Forensic Sci. 21, 868 (1976)
11. G. Capannesi, C. Ciavola and A.F. Sedda, Forensic Sci. Int. 61, 75 (1993).

12. D. De Gaetano and J.A. Siegel, J. Forensic Sci. 35, 1087 (1990).

13. M. Ueyama, R.L. Taylor and T.T. Noguchi, Scan. Electr. Microsc. 1, 367 (1980).

14. G.N. Rutty, P. Boyce, C.E. Robinson, A.J. Jeffrey and B. Morgan, Int. J. Legal Med. 122, 1 (2008).

15. K.M. Stein, M.L. Bahner, J. Merkel, S. Ain and R. Mattern, Int. J. Legal Med. 114, 15 (2000).

16. S.P. Sharma and S.C. Lahiri, Sci. Justice 49, 197 (2009).

17. A. Santos, T. Magalhães, D.N. Vieira, A.A. Almeida and A.V. Sousa, Am. J. Forensic Med. Pathol. 28, 24 (2007).

18. A. Zeichner, Anal. Bioanal. Chem. 376, 1178 (2003).

19. R. S. Nesbitt, J.E. Wessel, and P. F. Jones, J. Forensic Sci, 21(3), 595 (1976).

20. M.J. Bailey, K.J. Kirkby, and C. Jeynes, X-Ray Spectrometry 38(3), 190 (2009).

21. International Conference on Harmonization (ICH) of Technical Requirements for the Registration of Pharmaceuticals for Human Use, Validation of Analytical Procedures: Methodology (ICBQ2B) (1996).

22. B. Yüksel, Z. Kayaalti, T. Söylemezoğlu, V.A, Türksoy and E. Tutkun, At. Spectrosc. 36(4), 171 (2015).

23. A. Zeichner and N. Levin, J. Forensic Sci. 42(6), 1027 (1997).

24. S.S. Krishnan. J. Forensic Sci. 22(2), 304 (1997).

25. H. Meng and B. Caddy. J. Forensic Sci. 42(4), 553 (1997).

26. T Jalanti and P. Henchoz, Science \& Justice 39(1), 48 (1999).

27. V.J. Di Maio, Gunshot Wounds: Practical Aspects of firearms, ballistics, and forensic techniques, Boca Raton, FL, USA, CRC Press, 2nd edition, 346 (1999).

28. J. Andrasko and A.C. Maehly, J. Forensic Sci. 22(2), 279 (1977).

29. A. Zeichner and N. Levin. J. Forensic Sci. 38(3), 571 (1993). 